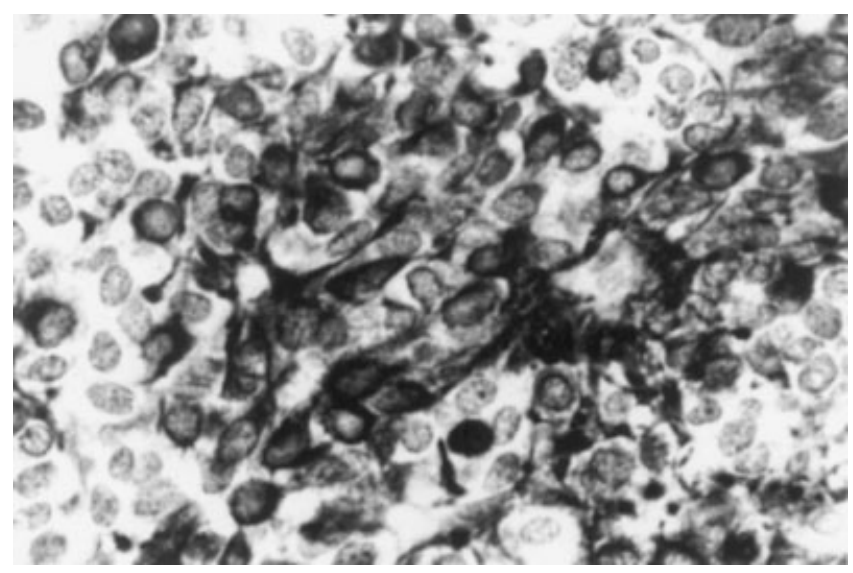

Fig. 3. Pulmonary metastasis, consisting of anaplastic cells, immunohistochemically strongly positive for glial acidic fibrillary protein (GFAP, $\times 600$ ).

differentiation and histologic type of the ependymoma, age at diagnosis, degree of surgical resection or prior treatment and subsequent development of extraneural metastases was found [4]. The exact route of extraneural metastases is not known, but in the vast majority metastases occurred in the wake of craniotomy, suggesting iatrogenic vascular seeding [3]. Typically, extraneural metastases of ependymoma occur in the lungs, pleura, and lymph nodes while metastases to the mediastinum, liver, bone, and diaphragmatic muscle are even less common [4]. In most cases, the existence of pleuropulmonary metastases was disclosed only at autopsy usually coexisting with CNS recurrence and systemic metastases [5]. Extraneural metastases or relapses of ependymoma are extremely rare but physicians caring for ependymoma patients must remain aware of this possible complication.

\section{REFERENCES}

1. Heidemann RL, Packer RJ, Albright LA, et al. Tumors of the central nervous system. In: Pizzo PA, Poplack DG, editors. Principles and practice of pediatric oncology. Philadelphia: Lippincott-Ravens; 1997. pp 633-697.

2. Smith DR, Hardman JM, Earle KM. Metastasizing neuroectodermal tumors of the central nervous system. J Neurosurg 1969;31:50-58.

3. Itoh J, Usui K, Itho M, et al. Extranial metastases of malignant ependymoma Neurol Med Chir (Tokyo) 1990;30:339-345.

4. Newton HB, Henson J, Walker RW. Extraneural metastases in ependymoma J Neurooncol 1992;14:135-142.

5. Lioté HA, Vedrenne C, Schlienger M, et al. Late pleuropulmonary metastases of a cerebral ependymoma. Chest 1988;94:1097-1098.

\title{
Thoracic Neural Crest Tumors in Beckwith-Wiedemann Syndrome
}

\author{
Courtney D. Thornburg, MD, ${ }^{1}$ Barry L. Shulkin, $\mathrm{MD}^{2}{ }^{2}$ Valerie P. Castle, $\mathrm{MD},{ }^{1}$ \\ and Linda M. McAllister-Lucas, $\mathrm{MD}$, $\mathrm{PhD}^{1}$ *
}

Key words: Beckwith-Wiedemann syndrome; cancer; neural crest tumor; screening

Beckwith-Wiedemann syndrome (BWS) is an overgrowth syndrome associated with increased birth weight, macroglossia, omphalocele, neonatal hypoglycemia, craniofacialanomalies, and visceromegaly [1,2]. The syndrome is a complex genetic disorder caused by dysregulation of multiple growth regulatory genes within the $11 \mathrm{p} 15$ region. It is a cancer predisposition syndrome, and at least $7.5 \%$ of patients develop a malignant disease; most commonly Wilms tumor [3]. Other embryonal tumors have been reported including hepatoblastoma and rhabdomyosarcoma, but neural crest tumors are rare. We, therefore, add to the literature two children with BWS in whom thoracic ganglioneuroma and ganglioneuroblastoma were found.

The first child was diagnosed with BWS complicated by neonatal hypoglycemia, mild macroglossia, omphalocele and cleft palate. She did not have hemihypertrophy. At age 4 years, she underwent a cleft palate repair under general anesthesia when decreased air movement on the left side of her chest was noted. A chest radiograph revealed a large posterior mediastinal mass. Computed tomography (CT) of the chest, abdomen and pelvis showed a left-sided $5.3 \mathrm{~cm} \times 4.6 \mathrm{~cm} \times 7.4 \mathrm{~cm}$ posterior paraspinal mass with speckled calcification that proved to be ${ }^{123}$ meta-iodobenzylguanidine (MIBG) avid. There was no evi- dence of bone marrow involvement. A twenty-four hour urine collection showed an elevated vanillylmandelic acid (VMA) of $9.7 \mathrm{mg} /$ total volume (tv) (normal 0-4) and an elevated homovanillic acid (HVA) of $23.5 \mathrm{mg} / \mathrm{tv}$ (normal 0-10). Ferritin was $22.5 \mathrm{ng} / \mathrm{ml}$ (normal 10-55). The mass was completely excised, and ganglioneuroma was confirmed on histologic examination of the surgical specimen. No adjunctive radio-

\footnotetext{
${ }^{1}$ Department of Pediatrics/Division of Hematology/Oncology, University of Michigan Medical Center, Ann Arbor, Michigan

${ }^{2}$ Department of Radiology/Division of Pediatric Nuclear Medicine, University of Michigan Medical Center, Ann Arbor, Michigan

Grant sponsor: NIH (to C.D.T.); Grant number: T32-HL07622-16; Gran sponsor: NCI RO1 (to B.L.S.); Grant number: CA54216; Grant sponsor: Doris Duke Clinical Scientist Development Award (to L.M.M.); Grant sponsor: National Childhood Cancer Foundation (L.M.M. is the Laura and Greg Norman Research Fellow)

*Correspondence to: Dr. Linda M. McAllister-Lucas, Division of Pediatric Hematology/Oncology, 1500 East Medical Center Drive, L2110 Women's Hospital Box 0238, Ann Arbor, MI 48109. E-mail: lindaluc@umich.edu
}

Received 26 February 2003; Accepted 6 May 2003 
TABLE I. Cases of Children With Beckwith-Wiedemann Syndrome (BWS) and Neural Crest Tumor

\begin{tabular}{|c|c|c|c|c|c|c|}
\hline Case no. & Author/et al. & Location of tumor & Histology & $\begin{array}{c}\text { Urine } \\
\text { catecholamines }\end{array}$ & Symptoms & Hemihypertrophy \\
\hline 1 & Wiedemann [10] & Paraspinal & Ganglioneuroma & ND & Asymptomatic & Yes \\
\hline 2 & Sotelo-Avila [11] & Retroperitoneal & Ganglioneuroma & ND & ND & ND \\
\hline 3 & Emery [1] & Thoracic & Neuroblastoma & Normal & Respiratory distress & No \\
\hline 4 & Sirinelli [4] & Thoracic & Neuroblastoma & Elevated & Asymptomatic & Yes \\
\hline 5 & Sirinelli [4] & Thoracic & Ganglioneuroma & Normal & Asymptomatic & No \\
\hline 6 & Huber [8] & Thoracic & Neuroblastoma & Normal & Asymptomatic & No \\
\hline 7 & Chitayat [7] & Adrenal & Ganglioneuroblastoma & ND & ND & No \\
\hline 8 & DeBaun [9] & ND & Neuroblastoma & ND & ND & ND \\
\hline 9 & DeBaun [9] & ND & Neuroblastoma & ND & ND & ND \\
\hline 10 & Yoon [12] & Thoracic & Ganglioneuroblastoma & Elevated & Respiratory distress & No \\
\hline 11 & Thornburg & Thoracic & Ganglioneuroma & Elevated & Respiratory distress & No \\
\hline 12 & Thornburg & Thoracic and pararenal & Ganglioneuroblastoma & Elevated & Abdominal Mass & Yes \\
\hline
\end{tabular}

ND, not described.

therapy or chemotherapy was given, and the patient is now 5-year-old without recurrence or development of Wilms tumor.

A second child was diagnosed with BWS at birth. Her course was complicated by hypoglycemia, macroglossia, omphalocele, and right-sided hemihypertrophy. At eighteen months of age, she presented with an abdominal mass. On chest, abdomen, and pelvis CT, she was found to have a $5 \mathrm{~cm} \times$ $5 \mathrm{~cm} \times 7 \mathrm{~cm}$ abdominal mass anterior to the left kidney and also a $2 \mathrm{~cm} \times 2 \mathrm{~cm} \times 4 \mathrm{~cm}$ right thoracic paraspinal mass with speckled calcification. MIBG whole body scan showed uptake in the right paraspinal area and left pararenal area. A bone scan was negative as was the bone marrow evaluation. The urine VMA was $29 \mathrm{mg} / \mathrm{tv}$ (normal 0-1.5) and serum ferritin was $26 \mathrm{ng} / \mathrm{ml}$ (normal 10-55). The tumors were completely resected and assessed to be differentiating ganglioneuroblastomas. MYCN was non-amplified. The patient was diagnosed with two primary stage I ganglioneuroblastomas. She did not receive any chemotherapy or radiation therapy and has been in remission for 15 years.

\section{DISCUSSION}

Children with BWS are typically able to overcome hyperinsulinism, macroglossia, and omphalocele $[2,4]$. The long-term outcome is determined primarily by the development of a malignancy. Wilms tumor is the most frequently associated tumor. It has been recommended that children with BWS have abdominal ultrasonography every 3-4 months during childhood to screen for Wilms tumor $[2,5,6]$.

Neural crest tumors are much less frequently associated with BWS than Wilms tumor. Table I summarizes all of the reported cases to date, including the two we describe. Among them, there was a fairly even distribution between neuroblastoma, ganglioneuroblastoma, and ganglioneuroma. Urine catecholamine levels were elevated in four of the seven patients for whom this information was available. Also, $30 \%$ of the children had hemihypertrophy.

Most important, many of the tumors were found during evaluation of non-specific respiratory symptoms. Of the twelve reported cases of neural crest tumors in BWS, seven were thoracic in location. Therefore, abdominal ultrasound screening for detection of Wilms tumor would miss more than $50 \%$ of these neural crest tumors. Some clinicians have recommended periodic chest radiography with measurement of urinary HVA, VMA, and dopamine as a screening measure although the BWS Registry does not recommend specific screening measures for neural crest tumors [7-9]. Clinicians, thus, need to maintain a high index-of-suspicion for both thoracic and abdominal neural crest tumors in children with BWS.

\section{REFERENCES}

1. Emery LG, Shields M, Shah NR, et al. Neuroblastoma associated with Beckwith-Wiedemann syndrome. Cancer 1983;52:176-179.

2. Weng EY, Mortier GR, Graham JM, et al. Beckwith-Wiedemann syndrome. An update and review for the primary pediatrician. Clin Pediatr 1995;34: 317-326.

3. Wiedemann HR. Tumors and hemihypertrophy associated with Wiedemann-Beckwith syndrome. Eur J Pediatr 1983;141:129.

4. Sirinelli D, Silberman B, Baudon JJ, et al. Beckwith-Wiedemann syndrome and neural crest tumors. A report of two cases. Pediatr Radiol 1989;19:242245 .

5. Beckwith JB. Children at increased risk for Wilms tumor: Monitoring issues. J Pediatr 1998;132:377-379.

6. Choyke P, Siegel M, Craft A, et al. Screening for Wilms tumor in children with Beckwith-Wiedemann syndrome or idiopathic hemihypertrophy. Med Pediatr Oncol 1999;32:196-200.

7. Chitayat D, Friedman JM, Dimmick JE. Neuroblastoma in a child with Wiedemann-Beckwith syndrome. Am J Med Genet 1990;35:433-436.

8. Huber A, Gutjahr P. Mediastinal neuroblastoma in Wiedemann-Beckwith syndrome. Monatsschr Kinderheilkd 1989;137:243-244.

9. DeBaun MR, Tucker MA. Risk of cancer during the first 4 years of life in children from The Beckwith-Wiedemann Syndrome Registry. J Pediatr 1998;132:398-400.

10. Wiedemann HR. Exomphalos-Makroglossie-Gigantismus-Syndrom, Berardinelli-Seip-Syndrom, und Sotos-Syndrom-eine vergleichende betrachtung unter ausgewahlten aspekten. Z Kinderheilk 1973;115:193-207.

11. Sotelo-Avila A, Gonzalex-Crussi F, Fowler JW. Complete and incomplete forms of Beckwith-Wiedemann syndrome: Their oncogenic potential. J Pediatr 1980;96:47-50

12. Yoon G, Graham G, Weksberg R, et al. Neuroblastoma in a patient with the Beckwith-Wiedemann syndrome (BWS). Med Pediatr Oncol 2002;38: 193-199. 